ISSN 0103-9954

\title{
ANÁLISE QUALITATIVA DA ARBORIZAÇÃO URBANA DE 25 VIAS PÚBLICAS DA CIDADE DE ARACAJU-SE
}

\author{
QUALITATIVE ANALYZES OF THE URBAN TREES IN THE 25 MAIN STREETS OF ARACAJU \\ CITY-SE
}

\author{
Carla Zoaid Alves dos Santos ${ }^{1}$ Robério Anastácio Ferreira ${ }^{2}$ Leila Rafaela Santos ${ }^{3}$ \\ Lívia Isabela Santos $^{4}$ Silvio Henrique Gomes ${ }^{5}$ Dalva Angélica Santos da Graça ${ }^{6}$
}

\section{RESUMO}

A realização de análises qualitativas das árvores plantadas no ambiente urbano é essencial para a sua manutenção porque permite identificar os principais problemas e propor possíveis soluções. Dentro desse contexto, este trabalho foi realizado com o objetivo de avaliar o estado qualitativo da arborização das 25 principais vias públicas da cidade de Aracaju, capital do Estado de Sergipe. A análise foi realizada por meio de censo, no qual os indivíduos foram quantificados, identificados e caracterizados de acordo com os seguintes parâmetros: estado geral da árvore, equilíbrio geral, aspecto fitossanitário, intensidade de injúrias mecânicas, aspectos ecológicos, eventos fenológicos, interferências geradas pela relação árvoreconstrução/fiação, tipo de pavimentação e superficialidade de raízes. Foi observado também se os indivíduos sofreram algum tipo de manejo e, posteriormente, sugeridas quais as ações seriam necessárias para a sua adequação. Foram avaliados no total 3.595 indivíduos, distribuídos em 66 espécies. A maioria das árvores (46\%) apresentou um estado geral regular de qualidade, sendo os principais problemas observados a poda drástica executada em $31,2 \%$ dos indivíduos e a ação de insetos xilófagos (cupins). Dentre os problemas observados, os principais são a necessidade de poda de limpeza $(32,2 \%)$ e a substituição de indivíduos velhos e debilitados $(10,8 \%)$.

Palavras-chave: composição florística; fitossanidade; podas; avenidas.

\begin{abstract}
ABATRACT
The achievement of qualitative analyzes of the urban trees is essential for it's maintenance because it allows to identify the main problems and to propose the possible solutions. Considering this situation, this work was carried out to evaluate the qualitative status of urban trees of 25 main streets of the Aracaju city, capital from Sergipe State, Brazil. The analysis were performed by means of a census, where all the individuals were quantified, identified and characterized in accordance with the following parameters: general state of the tree, general balance, plant health, intensity of mechanical injuries, ecological aspects, phenological events, interference generated by tree in the buildings, type of paving and root superficiality. It was also

1 Engenheira Florestal, Mestra em Desenvolvimento e Meio Ambiente, Universidade Federal de Sergipe, Campus Universitário, Av. Marechal Rondom, s/n, Rosa Elze, CEP 491000-000, São Cristovão (SE), Brasil. carlazoaid@gmail.com

2 Engenheiro Florestal, Dr., Professor Associado do Departamento de Ciências Florestais, Universidade Federal de Sergipe, Campus Universitário, Av. Marechal Rondom, s/n, Rosa Elze, CEP 491000-000, São Cristovão (SE), Brasil.raf@ufs.br

3 Engenheira Florestal, Departamento de Ciências Florestais, Universidade Federal de Sergipe, Av. Marechal Rondom S/N, Rosa Elze, CEP 491000-000, São Cristovão (SE), Brasil. leilafloresta@hotmail.com

4 Engenheira Florestal, Departamento de Ciências Florestais, Universidade Federal de Sergipe, Campus Universitário, Av. Marechal Rondom, s/n, Rosa Elze, CEP 491000-000, São Cristovão (SE), Brasil. livia.santos@hotmail.com

5 Engenheiro Florestal, Departamento de Ciências Florestais, Universidade Federal de Sergipe, Av. Marechal Rondom, s/n, Rosa Elze, CEP 491000-000, São Cristovão (SE), Brasil. silviocrust@mtv.com.br

6 Engenheira Florestal, Departamento de Ciências Florestais, Universidade Federal de Sergipe, Av. Marechal Rondom, s/n, Rosa Elze, CEP 491000-000, São Cristovão (SE), Brasil. dalvasg@yahoo.com.br
\end{abstract}

Recebido para publicação em 30/05/2011 e aceito em 20/11/2013

Ci. Fl., v. 25, n. 3, jul.-set., 2015 
observed if the individuals had suffered some type of management and, subsequently, suggested the actions kind would be necessary for their adequacy. There were evaluated in total 3,595 individuals, distributed in 66 species. The most part of (46\%) shown a general regular state, where the main problems observed were: tree pruning in the $31,2 \%$ of the individuals and insects xylophages (termites). The main problems observed were: cleaning pruning $(32,2 \%)$ and the substitution of old and debilitated individuals $(10,8 \%)$.

Keywords: floristic composition; phyto-sanitary condition; pruning; urban streets.

\section{INTRODUÇÃO}

Os conflitos gerados pela implantação inadequada da arborização urbana podem ser observados nas interferências e prejuízos causados aos equipamentos e estrutura urbana, tais como: fiações elétricas, encanamentos, calhas, calçamentos, muros, postes de iluminação e sinalização. Estes problemas, fáceis de serem visualizados, contribuem para um manejo inadequado e prejudicial às árvores, sendo comum a observação de árvores podadas drasticamente e com muitos problemas fitossanitários causados pela presença de cupins, brocas e patógenos; injúrias físicas como anelamentos; caules ocos e podres; galhos lascados ou rachados, etc. (RIBEIRO, 2009). Esse cenário caracteriza o padrão observado, atualmente, em muitas cidades brasileiras, que é o de uma arborização irregular, inadequada e descontínua (SILVA et al., 2008).

Considerando-se esses aspectos, a análise qualitativa das árvores urbanas desempenha um papel fundamental no planejamento da arborização no momento em que permite prever o surgimento desses conflitos, identificar os atuais e propor soluções adequadas às características do local avaliado.

A falta de planejamento da arborização permite que iniciativas particulares, pontuais e desprovidas de conhecimento técnico adequado, ocupem os espaços com plantios irregulares de espécies sem compatibilidade com o planejamento anterior. Esse procedimento é muito comum e reflete a perda na eficiência da arborização em cumprir as suas funções de conforto físico e psíquico, causando muitas vezes, sérios prejuízos e transtornos (SILVA FILHO et al., 2002).

Depois de pensados e discutidos todos os aspectos que envolvem o planejamento da arborização urbana, é necessário elaborar um plano para a manutenção dessas áreas, pois não seria útil ter-se um projeto bem elaborado $\mathrm{e}$ bem executado se este não for continuado. No caso de projetos de jardinagem, paisagismo e, consequentemente, de arborização, algumas atividades de manejo são comumente necessárias para a sobrevivência e o bom desenvolvimento das árvores urbanas, lembrando que, se a implantação for bem planejada as manutenções necessárias serão diminuídas. Compreende-se como manejo de árvores urbanas o conjunto de técnicas necessárias para a sobrevivência e manutenção dessas, pois diferentemente das condições das florestas naturais, as árvores urbanas encontram adversidades que podem comprometer seu estabelecimento e desenvolvimento (GONÇALVES e PAIVA, 2006).

As atividades de manejo relativas ao estado fitossanitário dos indivíduos e às podas aplicadas são as mais complexas e onerosas no manejo de árvores urbanas, necessitando de um plano criterioso de ação e conhecimento técnico apropriado para uma correta aplicação das ações, diminuindo assim os custos e as demasiadas intervenções.

O inventário das árvores é uma ferramenta fundamental para as etapas de manejo, e no caso específico da arborização urbana, busca-se obter informações qualiquantitativas que possibilitam conhecer o patrimônio arbóreo e identificar as atividades de manejo mais necessárias. Devem também prever a recoleta temporária de dados para atualizar as informações, planejar novas ações e avaliar as metodologias aplicadas. A condição qualitativa das árvores urbanas geralmente é avaliada por meio de um parâmetro denominado fitossanidade, o qual avalia cada indivíduo visualmente, e através das suas características biológicas e aspecto físico geral, pode ser conhecido o "estado de saúde" da árvore (SILVA et al., 2007).

Diante desse contexto, este trabalho foi realizado com o objetivo de avaliar qualitativamente a arborização urbana das 25 principais vias públicas de Aracaju - SE e identificar os principais problemas e as principais necessidades para que se possa planejar um manejo adequado. 


\section{MATERIAL E MÉTODOS}

O presente trabalho foi realizado no município de Aracaju, capital do Estado de Sergipe, localizada na região litorânea, entre as coordenadas geográficas $10^{\circ} 55^{\prime} 56^{\prime \prime}$ de latitude Sul e $37^{\circ} 04^{\prime} 23^{\prime \prime}$ de longitude Oeste. Possui uma população de 544.039 habitantes e uma área de $174,05 \mathrm{~km}^{2}$ (IBGE, 2010). A análise foi realizada por meio de um censo nas 25 principais vias da cidade (Tabela 1 ), no período de outubro de 2009 a fevereiro de 2010. A identificação das espécies botânicas encontradas foi realizada por meio de comparação com materiais já existentes (exsicatas) e identificados que estão no Laboratório de Dendrologia e Ecologia
Florestal, do Departamento de Ciências Florestais, da Universidade Federal de Sergipe (UFS) e por meio de consultas a literaturas especializadas (LORENZI et al.,1996; LORENZI, 1998 e 2002; GRAF, 2003; LORENZI et al., 2003). A nomenclatura botânica está de acordo com APG III (2009).

O levantamento das informações qualitativas dos indivíduos arbóreos foi realizado com base no trabalho de Silva Filho et al. (2002), do qual foi adaptado o quadro de análise das características biológicas das árvores, considerandose as condições encontradas na cidade de Aracaju - SE. Os parâmetros selecionados foram analisados da seguinte forma:

I - Dimensões: foi tomada a altura total de cada

TABELA 1: Listagem das 25 vias públicas selecionadas para o inventário da arborização urbana, com sua respectiva localização e extensão no município de Aracaju, SE.

TABLE 1: List of 25 selected urban streets for the inventory of urban trees, with their location and extension in the city of Aracaju, Sergipe.

\begin{tabular}{|c|c|c|}
\hline Vias públicas & Localização/bairro & Extensão $(\mathrm{km})^{1}$ \\
\hline Av. Acrísio Cruz & Salgado Filho & $0,809 \mathrm{~km}$ \\
\hline Av. Anísio Azevedo & São José & $1,1 \mathrm{~km}$ \\
\hline Av. Augusto Franco & Siqueira Campos & $3,854 \mathrm{~km}$ \\
\hline Av. Augusto Maynard & São José & $0,766 \mathrm{~km}$ \\
\hline Av. Barão de Maruim & Cirurgia & $0,769 \mathrm{~km}$ \\
\hline Av. Beira Mar & 13 de Julho /Atalaia & $6,32 \mathrm{~km}$ \\
\hline Av. Desembargador Maynard & América & $1,887 \mathrm{~km}$ \\
\hline Av. Edésio Vieira de Melo & São José & $1,888 \mathrm{~km}$ \\
\hline Av. Francisco Porto & Salgado Filho & $1,470 \mathrm{~km}$ \\
\hline Av. Gonçalo Prado Rollemberg & Cirurgia & $1,823 \mathrm{~km}$ \\
\hline Av. Gonçalo Rollemberg Leite & Suiça & $1,237 \mathrm{~km}$ \\
\hline Av. Hermes Fontes & Grageru/Suiça & $2,53 \mathrm{~km}$ \\
\hline Av. Ivo do Prado & Centro & $1,226 \mathrm{~km}$ \\
\hline Av. José da Silva Ribeiro & América & $1,172 \mathrm{~km}$ \\
\hline Av. Maranhão & Santos Dumont & $3,207 \mathrm{~km}$ \\
\hline Av. Melício Machado & Atalaia & $2,44 \mathrm{~km}$ \\
\hline Av. Rio Branco & Centro & $0,319 \mathrm{~km}$ \\
\hline Av. São Paulo & Santos Dumont & $2,323 \mathrm{~km}$ \\
\hline Av. Simeão Sobral & Santo Antônio & $1,131 \mathrm{~km}$ \\
\hline Av. Tancredo Neves & Inácio Barbosa & $10,156 \mathrm{~km}$ \\
\hline Rua Estância & Cirurgia & $2,281 \mathrm{~km}$ \\
\hline Rua Itabaiana & Centro & $1,034 \mathrm{~km}$ \\
\hline Rua Itabaianinha & Centro & $0,376 \mathrm{~km}$ \\
\hline Rua Maruim & Centro & $2,209 \mathrm{~km}$ \\
\hline Rua Rafael de Aguiar & Pereira Lobo & $1,814 \mathrm{~km}$ \\
\hline Total & 25 & $54,141 \mathrm{~km}$ \\
\hline
\end{tabular}

${ }^{1}$ Fonte: ARACAJU (2010). 
árvore com o auxílio de um clinômetro eletrônico (Haglof-serial 27125).

II - Biologia: são os itens relativos ao estado biológico, fisiológico e fitossanitário das árvores, definidos da seguinte forma:

Estado Geral: condição geral que a árvore estava no período de análise, sendo classificado em: Ótimo - árvore vigorosa e sadia sem sinais de ataque de insetos, doenças ou injúrias mecânicas; arquitetura característica da espécie. Bom - médias condições de vigor e saúde; necessitava de pequenos reparos ou podas; apresentava descaracterização da forma e sinais de ataque de insetos, doença ou problemas fisiológicos. Regular - apresentava estado geral de início de declínio; ataque severo por inseto, doença ou injúria mecânica, descaracterizando sua arquitetura; problemas fisiológicos requerendo reparos. Péssimo - avançado e irreversível declínio; apresentava ataque muito severo por insetos, doenças ou injúrias mecânicas, descaracterizando sua arquitetura; problemas fisiológicos cujos reparos não resultarão em benefício para o indivíduo.

Equilíbrio geral: a árvore apresentava equilíbrio quando possuía caule reto e copa de mesmas proporções para todos os lados.

Fitossanidade: foram observadas as principais pragas, doenças e associações que ocorrem nos indivíduos arbóreos, identificando o causador do ataque pelo nome vulgar, listando os tipos mais comuns, o local de ataque e a intensidade dos ataques provocados, sendo classificados da seguinte forma: Leve - quando o organismo ou agente estava presente, porém, sem causar danos à árvore; Médio - quando o organismo ou agente estava presente, causando danos reparáveis à árvore; Severo - quando o organismo ou agente estava causando danos irreparáveis que poderiam levar a árvore a um declínio definitivo; Ausente - quando não existia nenhum tipo de ataque.

Injúrias: caracterizadas por atos de vandalismo e lesões mecânicas provocadas pela ação humana ou pela ação de ventos e chuvas (como quebra de galhos). O grau da injúria foi classificado como lesão leve - quando a injúria era de pequena proporção e a árvore podia promover a recuperação sem qualquer auxílio; lesão média - quando a injúria era considerável, mas a árvore podia ser recuperada mediante ações de controle e reparos; lesão severa - quando a lesão comprometia a sobrevivência da árvore.

Ecologia: principais tipos de associações ecológicas que a árvore mantém, tais como líquens, epífitas, ninhos e outros menos comuns.

Eventos fenológicos: foi observada a presença das fenofases floração e frutificação.

III - Entorno e interferências:

Localização: observa-se se a árvore está localizada nos canteiros centrais, nas calçadas ou dentro do imóvel.

Fiação/construções: foram observados os conflitos existentes entre as árvores e os equipamentos urbanos como a fiação elétrica e telefônica, posteamento, sinalização, iluminação e muro/construção, sendo considerados como: atual quando o equipamento urbano ou edificação estava em contato com alguma parte da árvore ou potencial - quando a espécie pelo seu crescimento normal ia entrar em contato com algum equipamento ou edificação.

Superficialidade de raízes: as raízes foram consideradas superficiais quando o seu desenvolvimento estava comprometendo as estruturas dos canteiros, calçadas, muros ou outros equipamentos urbanos.

IV - Definição de ações - foram definidas em duas categorias: ações executadas, quando foi observado algum tipo de atividade de poda no indivíduo anteriormente e ações recomendadas, as quais foram definidas como as ações que, conforme o diagnóstico geral da árvore, são necessárias para a manutenção, adequação ou recuperação do bom estado dos indivíduos.

As ações analisadas foram classificadas da seguinte forma:

Plantio: quando houve apenas o plantio do indivíduo, não identificando nenhum outro tipo de ação.

Podas: operação de remoção seletiva de ramos verdes ou secos de uma árvore. A classificação e o objetivo dos tipos de poda empregadas no estudo foram definidos de acordo com o trabalho de Gilman e Lilly (2005). Poda de condução - remoção seletiva de ramos ou galhos para promover uma elevação vertical da copa da árvore, compatibilizando-se, assim, a árvore com os edifícios, automóveis, transeuntes e paisagens. Poda de controle - remoção seletiva de ramos ou galhos para diminuir a altura ou a extensão de uma árvore. Este tipo de poda se pratica para minimizar os riscos de queda da árvore, desviar de linhas elétricas, edifícios ou outras estruturas e para melhorar a aparência da planta. Poda de limpeza - remoção seletiva de ramos 
ou galhos mortos, doentes ou quebrados. Poda severa - remoção drástica de galhos e ramos da árvore, descaracterizando a arquitetura natural da espécie e removendo grandes porcentagens de galhos e ramos (acima de $35 \%$ da copa), que podem comprometer o bom estado fisiológico do indivíduo podado.

Ampliação de canteiro: recomendado quando o tamanho do canteiro em que o indivíduo estava localizado é inadequado para o seu bom desenvolvimento.

Controle fitossanitário: recomendado quando havia incidência média ou severa de alguma doença ou praga na árvore.

Substituição: recomendada quando o indivíduo estava em um estado de declínio irreversível, no qual nenhuma ação de manejo podia recuperá-lo ou quando a árvore apresentava algum risco de queda.

\section{RESULTADOS E DISCUSSÃO}

Considerando-se as 25 vias públicas inventariadas, foram avaliados 3.595 indivíduos, pertencentes a 66 espécies. Destas, foram identificadas 58 que estão distribuídas em 21 famílias botânicas e 8 espécies não foram identificadas (Tabela 2).

Em relação aos parâmetros qualitativos, o estado geral da qualidade das árvores foi caracterizado como regular para $46 \%$, bom para $38 \%$, péssimo para $10 \%$ e ótimo para $6 \%$ dos indivíduos, como pode ser observado na Tabela 3 (síntese dos valores encontrados para os parâmetros qualitativos analisados).

A elevada quantidade de árvores em estado regular de qualidade (46\%) e considerando-se que este estado é caracterizado pelo início de declínio do indivíduo, define a urgência na elaboração e execução de um plano de manejo para manutenção dessas árvores. Nessa fase, a reparação dos danos ainda pode ser reversível e, dependendo da qualidade das manutenções e reparos empregados, os indivíduos podem recuperar o seu bom estado de qualidade. Dos $10 \%$ de árvores em estado péssimo, trinta e sete indivíduos apresentam risco de queda de galhos secos e treze apresentam risco eminente de queda. Desses treze, seis estão visualmente com o caule oco, caracterizando-se a necessidade de urgente remoção desses indivíduos.

As viasque apresentarammaior porcentagem de indivíduos em um estado bom foram: a Av. São
Paulo com 73\%, Av. Ivo do Prado e Rua Maruim com $60 \%$ e Av. Gonçalo Prado Rollemberg com 51,1\% dos indivíduos. Já as vias que apresentaram maior porcentagem de indivíduos em um estado péssimo foram: Av. Simeão Sobral com 27,5\%; Av. Hermes Fontes com 18,3\%; Rua Rafael de Aguiar com $16,6 \%$ e Rua Estância com 13,9\% dos indivíduos. Essas vias devem ser priorizadas em uma ação de planejamento da arborização urbana do município, devido ao grande número de indivíduos em um estado péssimo, caracterizado como um estágio de declínio acentuado e irreversível.

Os aspectos fitossanitários permitiram verificar o estado de "saúde" das árvores avaliadas. Nas vias, os principais organismos causadores de lesões e danos foram os insetos, responsáveis por $50,4 \%$ dos ataques; microrganismos com 7,9\% e ervas parasitas com 1\%. Ainda, alguns indivíduos foram atacados por mais de um organismo: $2,3 \%$ insetos e microrganismos; $1,1 \%$ inseto e erva parasita; $0,2 \%$ outros não identificados; $0,1 \%$ erva parasita e microrganismos e $0,1 \%$ atacados por todos os organismos identificados nesse trabalho, restando $36,8 \%$ de árvores sem nenhum tipo de ação danosa ao seu estado fitossanitário. Apesar do grande número de árvores com presença de organismos danosos a sua saúde, a intensidade dos ataques foi severa em apenas $6 \%$, sendo leve em $41 \%$ e média em $16 \%$ dos indivíduos.

Dentre os insetos identificados, os que causam maiores danos às árvores das vias públicas de Aracaju são os cupins, insetos que pertencem à ordem Isoptera, vivem associados em grupos, alimentam-se de celulose e são importantes agentes da ciclagem de nutrientes. Foi constatado que os ataques de cupim às árvores, estão diretamente relacionados ao manejo inadequado que esses indivíduos recebem, tais como: a demasiada execução de podas severas, a falta de remoção dos galhos velhos e secos e a falta de monitoramento dos ninhos arborícolas, que deveriam ser removidos periodicamente.

Em muitas árvores da cidade observaram-se verdadeiras galerias dentro dos troncos, provocadas pela ação desses insetos. Em trabalhos realizados no Rio de Janeiro e São Paulo, Fontes e Filho (1998), trabalhando com cupins urbanos, constataram que os cupins subterrâneos são os que mais interagem com as árvores urbanas, principalmente a espécie Coptotermes havilandi. Além disso, esses mesmos autores atribuíram os ataques ao manejo inadequado das plantas localizadas em microambientes 
TABELA 2: Família botânica, nome popular, número de indivíduos (NI), frequência (Fr\%) e origem das espécies arbóreas e palmeiras encontradas nas 25 principais vias públicas de Aracaju - SE.

TABLE 2: Family and botanical species, popular name, number of individuals (NI), frequency (Fr\%) and origin of tree species and palm trees found in the 25 main streets of Aracaju, Sergipe.

\begin{tabular}{|c|c|c|c|c|}
\hline Família botânica/ espécie & Nome popular & NI & $\mathrm{Fr} \%$ & Origem \\
\hline \multicolumn{5}{|l|}{ ANACARDIACEAE } \\
\hline Anacardium occidentale $\mathrm{L}$. & cajueiro & 204 & $5,67 \%$ & Nativa \\
\hline Mangifera indica $\mathrm{L}$. & mangueira & 38 & $1,06 \%$ & Exótica \\
\hline Myracrodruon urundeuva Fr. All & aroeira-do-sertão & 1 & $0,03 \%$ & Nativa \\
\hline Schinus terebinthifolius Raddi & aroeira & 23 & $0,64 \%$ & Nativa \\
\hline \multicolumn{5}{|l|}{ ANNONACEAE } \\
\hline Annona squamosa $\mathrm{L}$. & pinha & 10 & $0,28 \%$ & Exótica \\
\hline Annona muricata $\mathrm{L}$. & graviola & 2 & $0,06 \%$ & Exótica \\
\hline \multicolumn{5}{|l|}{ BIGNONIACEAE } \\
\hline Sphatodea nilotica Seem & espatódea & 2 & $0,06 \%$ & Exótica \\
\hline Tecoma stans (L.) Kunth & ipê-mirim & 6 & $0,17 \%$ & Exótica \\
\hline Tabebuia aurea (Manso) Benth. \& Hook. & craibeira & 114 & $3,17 \%$ & Nativa \\
\hline Tabebuia chrysotricha (Mart. Ex DC.) Standl. & ipê-amarelo-cascudo & 3 & $0,08 \%$ & Nativa \\
\hline Handroanthus impetiginosus (Mart. Ex DC.) Mattos & ipê-roxo-de-minas & 4 & $0,11 \%$ & Nativa \\
\hline $\begin{array}{l}\text { Handroanthus heptaphyllus (Vell.) Mattos } \\
\text { Tabebuia heptaphylla (Vell.) Tol. }\end{array}$ & ipê-roxo & 4 & $0,11 \%$ & Nativa \\
\hline Handroanthus serratifolius (A. H. Gentry) S. Grose. & ipê-amarelo & 12 & $0,33 \%$ & Nativa \\
\hline \multicolumn{5}{|l|}{ CASUARINACEAE } \\
\hline Casuarina equisetifolia J.R.\& G. Forst. & casuarina & 121 & $3,37 \%$ & Exótica \\
\hline \multicolumn{5}{|l|}{ CHRYSOBALANACEAE } \\
\hline Licania tomentosa (Benth.) Fritsch. & oiti & 292 & $8,12 \%$ & Nativa \\
\hline \multicolumn{5}{|l|}{ COMBRETACEAE } \\
\hline Terminalia catappa $\mathrm{L}$. & amendoeira & 257 & $7,15 \%$ & Exótica \\
\hline \multicolumn{5}{|l|}{ CYCADACEAE } \\
\hline Cycas revoluta Thunb. & cica & 8 & $0,22 \%$ & Exótica \\
\hline \multicolumn{5}{|l|}{ FABACEAE } \\
\hline Adenanthera pavonina $\mathrm{L}$. & tento-carolina & 5 & $0,14 \%$ & Exótica \\
\hline Andira fraxinifolia Benth. & angelim & 1 & $0,03 \%$ & Nativa \\
\hline Bauhinia forficata Link & pata-de-vaca & 1 & $0,03 \%$ & Nativa \\
\hline Caesalpinia echinata Lam. & pau-brasil & 14 & $0,39 \%$ & Nativa \\
\hline Libidibia ferrea var. leiostachya (Benth.) L.P.Queiroz & pau-ferro & 10 & $0,28 \%$ & Nativa \\
\hline Cassia fistula $\mathrm{L}$. & cassia-amarela & 27 & $0,75 \%$ & Exótica \\
\hline Cassia siamea Lam. & cassia-siamea & 7 & $0,19 \%$ & Exótica \\
\hline Clitoria fairchildiana Howard & sombreiro & 106 & $2,95 \%$ & Nativa \\
\hline Delonix regia (Bojer ex Hook.) Raf. & flamboyant & 30 & $0,83 \%$ & Exótica \\
\hline Erythrina indica Lam. & brasileirinho & 30 & $0,83 \%$ & Exótica \\
\hline Inga uruguensis Hook. \& Arn. & ingá-vera & 4 & $0,11 \%$ & Nativa \\
\hline
\end{tabular}


TABELA 2: Continuação...

TABLE 2: Continued...

\begin{tabular}{|c|c|c|c|c|}
\hline Família botânica/ espécie & Nome popular & NI & $\mathrm{Fr} \%$ & Origem \\
\hline Leucaena leucocephala (Lam.) R. de Wit & leucena & 19 & $0,53 \%$ & Exótica \\
\hline Lonchocarpus sericeus (Poir.) DC. & falso-ingá & 1 & $0,03 \%$ & Nativa \\
\hline Pithecellobium dulce (Roxb.) Benth. & mata-fome & 813 & $22,61 \%$ & Exótica \\
\hline Prosopis juliflora (Sw.) DC. & algaroba & 8 & $0,22 \%$ & Exótica \\
\hline Tamarindus indica $\mathrm{L}$. & tamarindo & 20 & $0,56 \%$ & Exótica \\
\hline \multicolumn{5}{|l|}{ MALVACEAE } \\
\hline Ceiba speciosa St. Hill & paineira & 1 & $0,03 \%$ & Nativa \\
\hline Pachira aquatica Aubl. & castanha-do-maranhão & 16 & $0,45 \%$ & Nativa \\
\hline Hybiscus pernambucensis Arruda & algodão-da-praia & 4 & $0,11 \%$ & Nativa \\
\hline \multicolumn{5}{|l|}{ MELIACEAE } \\
\hline Azadirachta indica A. Juss. & neem & 29 & $0,81 \%$ & Exótica \\
\hline Melia azedarach L. & cinamomo & 3 & $0,08 \%$ & Exótica \\
\hline \multicolumn{5}{|l|}{ MORACEAE } \\
\hline Artocarpus heterophyllus Lam. & jaqueira & 1 & $0,03 \%$ & Exótica \\
\hline Ficus benjamina L. & fícus & 672 & $18,69 \%$ & Exótica \\
\hline Ficus elastica Roxb. & fícus-elástica & 1 & $0,03 \%$ & Exótica \\
\hline Ficus microcarpa L. f. & ficus-microcarpa & 16 & $0,45 \%$ & Exótica \\
\hline \multicolumn{5}{|l|}{ MALPIGHIACEAE } \\
\hline Malpighia glabra L & acerola & 1 & $0,03 \%$ & Exótica \\
\hline \multicolumn{5}{|l|}{ MORINGACEAE } \\
\hline Moringa oleifera Lam. & moringa & 1 & $0,03 \%$ & Exótica \\
\hline \multicolumn{5}{|l|}{ MYRTACEAE } \\
\hline Eucalyptus grandis W. Hill ex Maiden & eucalipto & 2 & $0,06 \%$ & Exótica \\
\hline Psidium guajava L. & goiabeira & 4 & $0,11 \%$ & Nativa \\
\hline Syzygium cumini (L.) Skeels & jamelão & 18 & $0,50 \%$ & Exótica \\
\hline Syzygium malaccense (L.) Merr. \& L.M. Perry & jambeiro & 6 & $0,17 \%$ & Exótica \\
\hline \multicolumn{5}{|l|}{ PALMAE } \\
\hline Cocos nucifera L. & coqueiro & 348 & $9,68 \%$ & Exótica \\
\hline Dypsis lutenscens H. Wendl. & palmeira areca-bambu & 2 & $0,06 \%$ & Exótica \\
\hline Roystonea regia (H. B. K.) O. F. Cook & palmeira-imperial & 164 & $4,56 \%$ & Exótica \\
\hline Pritchardia pacifica Seemann \&H. Wendl. & palmeira leque-de-fiji & 8 & $0,22 \%$ & Exótica \\
\hline Veitchia merrillii (Becc) H. E. Moor & palmeira mini-imperial & 32 & $0,89 \%$ & Exótica \\
\hline Caryota mitis Lour. & palmeira rabo-de-peixe & 6 & $0,17 \%$ & Exótica \\
\hline morfo espécie 1 & palmeira & 1 & $0,03 \%$ & - \\
\hline morfo espécie 2 & palmeira & 1 & $0,03 \%$ & - \\
\hline morfo espécie 3 & palmeira & 1 & $0,03 \%$ & - \\
\hline \multicolumn{5}{|l|}{ POLYGONACEAE } \\
\hline Triplaris sp. & pau-de-formiga & 14 & $0,39 \%$ & - \\
\hline \multicolumn{5}{|l|}{ RUTACEAE } \\
\hline Citrus sp. & limoeiro & 9 & $0,25 \%$ & Exótica \\
\hline
\end{tabular}


TABELA 2: Continuação...

TABLE 2: Continued...

\begin{tabular}{|c|c|c|c|c|}
\hline Família botânica/ espécie & Nome popular & NI & $\mathrm{Fr} \%$ & Origem \\
\hline \multicolumn{5}{|l|}{ RUBIACEAE } \\
\hline Genipa americana L. & jenipapeiro & 1 & $0,03 \%$ & Nativa \\
\hline \multicolumn{5}{|l|}{ STERCULIACEAE } \\
\hline Sterculia chicha St. Hil. Ex Turpin & chicha & 4 & $0,11 \%$ & Nativa \\
\hline morfo espécie 4 & - & 17 & $0,47 \%$ & - \\
\hline morfo espécie 5 & - & 1 & $0,03 \%$ & - \\
\hline morfo espécie 6 & - & 1 & $0,03 \%$ & - \\
\hline morfo espécie 7 & - & 11 & $0,31 \%$ & - \\
\hline Total & 66 & 3595 & $100 \%$ & \\
\hline
\end{tabular}

TABELA 3: Valores percentuais dos parâmetros qualitativos das árvores avaliadas nas 25 principais vias públicas de Aracaju - SE.

TABELA 3: Percentage values of qualitative parameters of trees evaluated in the 25 main streets of Aracaju, Sergipe.

\begin{tabular}{|c|c|c|c|c|c|c|c|}
\hline \multicolumn{8}{|c|}{ I. Aspectos Biológicos } \\
\hline \multicolumn{3}{|c|}{ Estado Geral } & \multicolumn{3}{|c|}{ Fitossanidade } & \multicolumn{2}{|c|}{ Injúria } \\
\hline \multicolumn{2}{|c|}{ Ótimo } & $6 \%$ & Leve & \multicolumn{2}{|c|}{$41 \%$} & Leve & $24 \%$ \\
\hline \multicolumn{2}{|c|}{ Bom } & $38 \%$ & Média & & & Média & $9 \%$ \\
\hline \multicolumn{2}{|c|}{ Regular } & $46 \%$ & Severa & & & Severa & $3 \%$ \\
\hline \multicolumn{2}{|c|}{ Péssimo } & $10 \%$ & Ausente & & & Ausente & $64 \%$ \\
\hline \multicolumn{3}{|c|}{ Associações Ecológicas } & \multicolumn{3}{|c|}{ Eventos Fenológicos } & \multicolumn{2}{|c|}{ Equilíbrio } \\
\hline \multicolumn{2}{|c|}{ Liquens } & $59 \%$ & Folha & & $4 \%$ & Sim & $58 \%$ \\
\hline \multicolumn{2}{|c|}{ Ninhos } & $0,4 \%$ & Flor & & $\%$ & Não & $42 \%$ \\
\hline \multicolumn{2}{|c|}{ Epífitas } & $0,4 \%$ & Fruto & & $3 \%$ & & \\
\hline \multicolumn{2}{|c|}{ Líquens e Ninhos } & $1,9 \%$ & Flor e fruto & & $6 \%$ & & \\
\hline \multicolumn{2}{|c|}{ Líquens e epífitas } & $0,92 \%$ & Ausente & & $\%$ & & \\
\hline \multicolumn{2}{|c|}{ Ninhos e epífitas } & $0,08 \%$ & & & & & \\
\hline \multicolumn{2}{|c|}{ Ausente } & $37,7 \%$ & & & & & \\
\hline \multicolumn{8}{|c|}{ II. Interferências e Entornos } \\
\hline \multicolumn{2}{|c|}{ Localização } & \multicolumn{2}{|c|}{ Fiação/muros } & \multicolumn{2}{|c|}{ Sup. Raízes } & \multicolumn{2}{|c|}{ Pavimentação } \\
\hline Canteiro & $64,6 \%$ & Atual & $15 \%$ & Sim & $33 \%$ & Cimento & $10 \%$ \\
\hline Calçada & $35,3 \%$ & Potencial & $12 \%$ & Não & $67 \%$ & Terra/Grama & $90 \%$ \\
\hline Imóvel & $0,1 \%$ & Ausente & $73 \%$ & & & & \\
\hline
\end{tabular}

inadequados, sob influências de injúrias mecânicas, tratos culturais incorretos, o uso de espécies exóticas e a dificuldade de localizar e controlar os ninhos, que à medida que as colônias se estabelecem permanecem por muitos anos no local e tornam-se mais daninhos com o envelhecimento natural das árvores.

Autores que fizeram análises semelhantes também confirmaram que a falta de manutenção das árvores e o manejo inadequado são as principais causas que contribuem para o alto índice de indivíduos em um estado ruim ou regular de qualidade. Por exemplo, em Maringá - PR, Sampaio e Angelis (2008) encontraram 35,52\% das árvores em condições ruins e em 13,72\% destas havia a presença de cupim, sendo essa frequência 
mais alta naquelas zonas que as árvores são mais velhas. Em Jacareí - SP, Faria et al. (2007), usando a mesma metodologia desse trabalho, encontraram $44 \%$ das árvores em estado regular e $16 \%$ estavam em avançado declínio, apresentando ataque severo por insetos, doença ou injúria mecânica e arquitetura descaracterizada devido a podas severas, promovendo o desequilíbrio do vegetal, com risco de tombamento. Os autores concluíram que há a necessidade de um programa de podas adotando critérios e técnicas adequadas para a manutenção da qualidade dessas árvores.

As ervas parasitas também se apresentam como um problema fitossanitário bastante comum na arborização das cidades brasileiras. Nas vias de Aracaju, a única presente foi a erva-depassarinho, pertencente à família Loranthaceae. Apesar de apenas $1,1 \%$ das árvores avaliadas estarem infestadas, devido ao grande potencial danoso que essas ervas apresentam, a remoção e o constante monitoramento são necessários, a fim de se evitar essas infestações, que em alguns anos pode ocasionar a morte da planta hospedeira. Em outras cidades brasileiras os índices encontrados para essa infestação foram bem mais elevados, por exemplo, na cidade de Curitiba - PR, Leal et al. (2006) encontraram em $28,19 \%$ das árvores amostradas, a presença de erva-de-passarinho, aproximando-se também dos valores encontrados por Rotta (2004) em um passeio público de Curitiba que estimou que o hemiparasita ocorre em $30 \%$ da arborização da cidade.

O equilíbrio geral define a boa relação do caule e copa das árvores. Nas avenidas inventariadas, $42 \%$ dos indivíduos não apresentaram esse equilíbrio e $58 \%$ estão equilibrados. A falta de equilíbrio das árvores pode ser provocada por vários fatores tais como: consecutivas podas mal executadas, impedimentos físicos ao seu crescimento natural, ou ainda, isso pode ser decorrente da ação de ventos costeiros predominantes, como ocorre na Av. Ivo do Prado, na qual 52,6\% das árvores apresentam desequilíbrio devido a esse fator, sendo Licania tomentosa (oiti) a espécie mais afetada, com 77,6\% dos indivíduos apresentando desequilíbrio.

Ações de injúrias foram observadas em $36 \%$ dos indivíduos avaliados, sendo classificadas com base na intensidade da lesão como leves em 24\%, médias em $9 \%$ e severas em apenas $3 \%$. Observou-se que $64 \%$ dos indivíduos não sofreram nenhum tipo de injúria. As lesões físicas provocadas pela ação de ventos ou chuvas foram mínimas, enquanto as ações de vandalismo da população foram as principais responsáveis pelas lesões, caracterizadas pelas mais diversas práticas como: pregos colocados no tronco; arames, cordas e fios enrolados nos troncos com alguns causando estrangulamento do mesmo; caiações e pinturas no caule; descascamentos, anelamentos e ferimentos provocados por objetos cortantes (facas, facões e foices); acúmulo de lixo na parte basal e nos galhos da árvore; uso das árvores como suporte para enfeites e faixas, dentre outros. Teixeira (1999), na cidade de Santa Maria - RS, observou que 12,5\% das árvores avaliadas também sofreram danos semelhantes provocados por vandalismos. Esses problemas caracterizam a necessidade de se incluir planos de Educação Ambiental nos programas de arborização urbana, nos quais a população possa participar diretamente das ações de implantação e manutenção da arborização na cidade.

Em relação às associações ecológicas, a interação mais significativa presente nas árvores de Aracaju é com líquens $(61,8 \%)$ que são resultantes da associação mutualística entre fungos e algas presentes no tronco das árvores e são considerados bons bioindicadores da qualidade do ar, por serem sensíveis à poluição, principalmente ao dióxido de enxofre, flouretos, ozônio e outros. Quando presentes em grande quantidade nos troncos das árvores, geralmente indicam que nesse local o nível de poluição do ar está baixo e adequado para as plantas e para o homem (SILVA et al., 1999). Esses tipos de associações são importantes para o ecossistema urbano porque oferecem benefícios para as árvores, para a fauna, para o ambiente físico e, consequentemente, para a população.

Durante a época de coleta dos dados, $56,4 \%$ das árvores estavam somente com folhas, $24,3 \%$ estavam com fruto, $12,6 \%$ estavam com flor e fruto, $6,6 \%$ apenas com flor e $0,1 \%$ sem nenhuma estrutura vegetativa ou reprodutiva. $O$ registro da época de floração e frutificação das espécies que compõem a arborização urbana é importante para definir a época de poda mais adequada para cada espécie. As podas devem ser evitadas nesses períodos porque é a época que as espécies reservam a sua energia para a fase de reprodução. Serve também para efeito de planejamento da coleta de frutos grandes como os das espécies: Cocus nucifera (coqueiro), Mangifera indica (mangueira), Pachira aquatica (castanha-domaranhão) e Annona muricata (graviola).

Foi observado que $64,6 \%$ das árvores presentes nas vias públicas de Aracaju estão 
localizadas nos canteiros centrais, $35,3 \%$ nas calçadas laterais e $0,1 \%$ dentro de imóveis. Apenas $12 \%$ estão sob interferência dos equipamentos urbanos, $15 \%$ poderão potencialmente estar sob interferência pelo seu crescimento natural e $73 \%$ estão livres de qualquer tipo de interferência. Isso demonstra a potencialidade dessas vias de serem arborizadas com espécies de porte elevado, as quais proporcionam uma maior área sombreada.

Outro problema bastante comum na arborização das cidades brasileiras é a implantação de espécies que apresentam sistema radicular superficial. Dessa forma, conhecer as espécies que apresentam essa característica, no planejamento da arborização urbana, constitui uma análise fundamental. Espécies que apresentam raízes com crescimento radicial superficial e pouco crescimento em profundidade, geralmente provocam problemas na arborização das vias, destruindo calçadas e canteiros, e, muitas vezes, comprometendo a estrutura de imóveis. A falta de espaço adequado nos canteiros para o desenvolvimento da árvore é uma das principais causas destes conflitos entre esse tipo de raiz e os elementos do meio. Nesse trabalho, dentre as espécies que apresentam como característica raízes superficiais pode-se observar que 33\% das árvores avaliadas apresentaram conflitos com meio devido a esse fator, sendo que a espécie com o maior número de indivíduos causando problemas foi o Ficus benjamina (fícus) seguido da Terminalia catappa

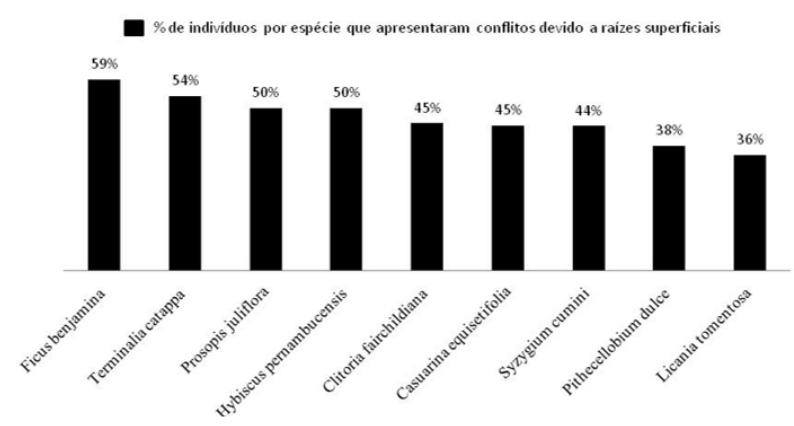

FIGURA 1: Porcentagem de árvores por espécie que mais apresentaram problemas devido à superficialidade das raízes nas 25 principais vias públicas avaliadas, na cidade de Aracaju - SE.

FIGURE 1: Percentage of tree by species that were more problem because the shallow roots in the top 25 main streets assessed in the city of Aracaju, Sergipe. (amendoeira) e da Prosopis juliflora (algaroba) (Figura 1).

O tipo de pavimentação predominante ao redor das árvores (área de drenagem) foi a cobertura de terra/grama presente em $90 \%$ das vias avaliadas e $10 \%$ estavam pavimentadas com cimento. O ideal era que $100 \%$ dos canteiros das árvores apresentassem o tipo de pavimentação terra/ grama, pois a pavimentação com cimento impede a infiltração da água na área ocupada pela árvore, podendo ocasionar problemas de deficit hídrico e ausência de aeração das raízes.

Em relação às ações executadas, apesar de apenas $12 \%$ das árvores apresentarem algum tipo de interferência com os equipamentos urbanos (energia, telefonia, edificações e sinalização), mais de $30 \%$ dessas sofrem podas severas (drásticas), sendo esse tipo de ação a mais executada nas vias públicas de Aracaju; 21,2\% ainda não sofreram nenhum tipo de manejo, apenas o plantio; 18,2\% sofreram poda de controle; $17,3 \%$ poda de condução; $7,9 \%$ poda de condução e de controle; $2,5 \%$ poda de controle e poda severa; $1,3 \%$ poda de condução e poda severa e $0,3 \%$ todas as podas classificadas neste trabalho (Tabela 4).

Em outras cidades, os valores das podas drásticas foram menores. Em Várzea Grande - MG, Moura e Santos (2009) encontraram apenas 4\% das árvores com esse tipo de poda e em Ponta Grossa - PR, Miranda e Carvalho (2009) observaram que

TABELA 4: Percentual das ações executadas nos indivíduos arbóreos presentes nas 25 principais vias públicas de Aracaju SE.

TABLE 4: Percentage of actions performed on individuals trees present in the 25 main streets of Aracaju, Sergipe.

\begin{tabular}{lcc}
\hline \multicolumn{1}{c}{ Ações Executadas } & $\%$ & NI \\
\hline Poda severa & 31,2 & 1122 \\
Plantio & 21,2 & 762 \\
Poda de controle & 18,2 & 655 \\
Poda de condução & 17,3 & 623 \\
P. Condução - P. Controle & 7,9 & 285 \\
P. Controle - P. Severa & 2,5 & 91 \\
P. Condução - P. Severa & 1,3 & 46 \\
P. Controle - P. Severa - P. condução & 0,3 & 11 \\
\hline \multicolumn{1}{c}{ Total } & 100 & 3595 \\
\hline
\end{tabular}

Em que: $\mathrm{NI}=$ Número de indivíduos. 
TABELA 5: Porcentual das ações de manejo recomendadas para a manutenção dos indivíduos arbóreos das 25 principais vias públicas de Aracaju - SE.

TABELA 5: Percentage of management actions recommended for the maintenance of tree individuals in the 25 main streets of Aracaju - SE.

\begin{tabular}{lcc}
\hline \multicolumn{1}{c}{ Ações Recomendadas } & $\%$ & NI \\
\hline Ampliação de canteiro & 1,9 & 67 \\
Controle fitossanitário & 1,0 & 35 \\
Controle fitossánitario - Ampliação de canteiro & 0,1 & 2 \\
Poda de condução & 7,7 & 278 \\
Poda de controle & 3,8 & 137 \\
Poda de limpeza & 32,2 & 1156 \\
P. Condução - Ampliação de canteiro & 0,03 & 1 \\
P. Condução - P. Controle & 1,6 & 58 \\
P. Condução - Tutoramento & 0,3 & 9 \\
P. Limpeza - P. Condução & 8,5 & 307 \\
P. Limpeza - P. Controle & 8,3 & 298 \\
P. Limpeza - P. Controle - P. Condução & 0,3 & 11 \\
P. Manutenção - Controle fitossanitário & 3,0 & 107 \\
P. Manutenção - Ampliação de canteiro & 6,1 & 218 \\
Substituição & 10,8 & 390 \\
Tutoramento & 0,2 & 8 \\
Todas as ações recomendadas & 0,3 & 12 \\
Nenhuma & 13,9 & 501 \\
\hline \multicolumn{1}{c}{ Total } & $100 \%$ & 3.595 \\
\hline
\end{tabular}

Em que: NI = Número de indivíduos.

$9,5 \%$ do total de espécies sofreram poda severa e, à semelhança do que acontece em Aracaju, algumas acabam morrendo devido à execução inadequada da poda.

A falta de planejamento também contribui para o mau manejo da arborização, muitas espécies são plantadas em locais inadequados ao seu desenvolvimento, necessitando de um intenso ciclo de podas para evitar conflitos e interferências com equipamentos urbanos. Além disso, observa-se uma ausência de qualificação técnica das equipes que realizam o manejo das árvores em Aracaju, uma vez que comumente não usam equipamentos de segurança individual (EPIs), as ferramentas são precárias e inadequadas, expondo o trabalhador a riscos de acidentes. A falta de conhecimento técnico atualizado ocasiona a constante prática de verdadeiras mutilações nas árvores urbanas.

As ações de um plano de manejo para arborização de uma cidade não devem ser unidirecionais e nem decididas antes de se conhecer o real estado da comunidade arbórea, e para as vias públicas inventariadas em Aracaju, o rol dessas ações é bastante significativo. Detectou-se que $32,2 \%$ das árvores necessitam de podas de limpeza, sendo essa ação a mais necessária; $13,9 \%$ não precisam de nenhum tipo de ação; $10,8 \%$ necessitam ser substituídas; $8,5 \%$ necessitam de poda de limpeza e de condução; 8,3\% necessitam de poda de limpeza e de controle; $7,7 \%$ de poda de condução; $6,1 \%$ além das podas de manutenção, a ampliação dos canteiros; $3,8 \%$ de poda de controle; $3 \%$ podas de manutenção e controle fitossanitário; $1,9 \%$ ampliação dos canteiros; $1,6 \%$ podas de condução e podas de controle; $1 \%$ controle fitossanitário; $0,3 \%$ de todos os tipos de poda de manutenção; $0,3 \%$ de poda de condução e tutoramento; $0,3 \%$ necessitam de todas as ações, neste trabalho recomendadas; $0,2 \%$ necessitam de tutoramento e $0,03 \%$ necessitam de poda de condução e ampliação dos canteiros (Tabela 5).

A Av. Augusto Maynard é uma das avenidas mais bem arborizadas de Aracaju. O ideal seria que as outras avenidas fossem adequadas ao 
padrão da Augusto Maynard, que ao longo de sua extensão forma uma alameda, a qual propicia um sombreamento efetivo muito maior do que o de outras avenidas com um número superior de árvores. Em Nova Iguaçu - RJ, Rocha et al. (2004) também constataram que em relação ao manejo das árvores a principal necessidade é a poda de limpeza (em 77,1\% dos indivíduos). Já em Santa Maria - RS, Teixeira (1999) constatou que essa necessidade era de $44 \%$ (classificada no trabalho como poda leve).

Como observado, Aracaju apresenta o mesmo cenário visto na maioria das cidades brasileiras que conforme Silva et al. (2008), é o de uma arborização irregular, inadequada e descontínua, devido a vários fatores, como os apresentados nesse trabalho.

$\mathrm{O}$ que falta às demais cidades brasileiras é a elaboração de Planos Diretores para a adequação da arborização urbana semelhantes aos das cidades de Porto Alegre - RS (PORTO ALEGRE, 2007), Goiânia - GO (GOIÂNIA, 2007) e Vitória - ES (VITÓRIA, 1992), que visam a uma correta implantação e manutenção da arborização urbana dessas cidades, adotando critérios técnicos associados ao planejamento urbano e aos inventários do seu patrimônio arbóreo.

\section{CONCLUSÕES}

As árvores presentes nas 25 principais vias públicas de Aracaju - SE apresentam um estado regular de qualidade, necessitando de um plano de manejo para manutenção e adequação da arborização nesses locais.

Os principais agentes causadores de problemas fitossanitários às árvores são os cupins e os fungos apodrecedores, que estão associados à alta porcentagem de podas severas executadas, à falta de monitoramento dos ninhos arborícolas e à falta de podas de limpeza dos galhos velhos, podres e mortos.

Agrande quantidade de ações recomendadas, principalmente a poda de limpeza, demonstra que a qualidade da arborização das vias públicas de Aracaju precisa ser monitorada e adequada a padrões técnicos de manutenção mais eficientes.

\section{REFERÊNCIAS BIBLIOGRÁFICAS}

ARACAJU. Secretaria Municipal de Planejamento - SEPLAN/Prefeitura Municipal de Aracaju. Extensão de 25 vias públicas. Aracaju, 2010.
AGP. Angiosperm Phylogeny Group, EUA. 2009. FARIA, J. L. G.; MONTEIRO, E. A.; FISCH, S. T. V. Arborização de vias públicas do município de Jacareí - SP. Revista SBAU, Piracicaba, v. 2, n. 4, p. 20-33. 2007.

FONTES, L. R.; FILHO, E. B. (Ed.). Cupins: o desafio do conhecimento. Piracicaba: FEALQ, 1998, $512 \mathrm{p}$.

GILMAN, E. F.; LILLY, S. J. Mejores Prácticas de Manejo: poda de àrboles. Champaing: ISA Sociedad Internacional de Arboricultura, 2005.

GOIÂNIA. Prefeitura Municipal de Goiânia. Plano Diretor de Arborização Urbana de Goiânia. Goiânia, 2007.

GONÇALVES, W.; PAIVA, H. N. Silvicultura Urbana: implantação e manejo. Viçosa: Aprenda Fácil, 2006. 201 p. (Coleção Jardinagem e Paisagismo, série Arborização Urbana, v.4).

GRAF, A. B. Tropica: Color Cyclopedia of Exotic plants and trees. Farmingdale: ROEHRS, 5th ed, 2003. $1152 \mathrm{p}$.

IBGE-INSTITUTO BRASILEIRO DE GEOGRAFIA E ESTATÍSTICA. Disponível em: $<$ (http://www.ibge.gov.br/cidadesat/topwindow. htm?)> Acesso em: 31/01/2010.

LEAL, L. BUJOKAS, W. M.; BIONDI, D. Análise da infestação de erva-de-passarinho na arborização de ruas de Curitiba-PR. Floresta, Curitiba, v. 36, n. 3, p.323-330, dez, 2006.

LORENZI, H. Árvores Brasileiras: Manual de Identificação e Cultivo de Plantas Arbóreas do Brasil. Nova Odessa: Plantarum, v. 2, 2. ed. 1998. $352 \mathrm{p}$.

LORENZI, H. Árvores Brasileiras: Manual de Identificação e Cultivo de Plantas Arbóreas do Brasil. Nova Odessa: Plantarum, v. 1, 4. ed. 2002. $368 \mathrm{p}$.

LORENZI, H. et al. Árvores exóticas no Brasil: madeireiras, ornamentais e aromáticas. Nova Odessa: Plantarum, 2003. 368 p.

LORENZI, H. et al. Palmeiras no Brasil: nativas e exóticas. Nova Odessa: Plantarum, 1996. 303 p.

MIRANDA, T. O. de; CARVALHO S. M. Levantamento quantitativo e qualitativo de indivíduos arbóreos presentes nas vias do Bairro da Ronda em Ponta Grossa - PR. Revista SBAU, Piracicaba, v. 4, n. 3, p. 143-157, 2009.

PORTO ALEGRE. Secretaria Municipal do Meio Ambiente. Plano Diretor de Arborização Urbana de Porto Alegre. Porto Alegre, 2007. 36 p.

MOURA, T. A. de; SANTOS, V. L. L. V. Levantamento quali-quantitativo de espécies 
arbóreas e arbustivas na arborização viária urbana dos bairros centro e centro norte, Várzea Grande, Mato Grosso, Brasil. Revista SBAU, Piracicaba, v. 1, n. 1, p. 97-117, 2009.

RIBEIRO, F. A. B. S. Arborização Urbana em Uberlândia: percepção da população. Revista da Católica, Uberlândia, v. 1, n. 1, p. 224-237, 2009.

ROCHA, R. T. da; LELES, P. S. S. dos; NETO, S. N. O. de. Arborização de vias públicas em Nova Iguaçu, RJ: o caso dos bairros Rancho Novo e Centro. Revista Árvore, Viçosa, v. 28, n. 4, p. 599-607, 2004.

ROTTA, E. Autrofia em Tripodanthus acutifolius (Ruiz \& Pai) Thiegh. (erva-de-passarinho) - um registro. Colombo: EMBRAPA, 2004. (Comunicado técnico, n.115)

SAMPAIO, A. C. F.; ANGELIS, B. L. D. de. Inventário e análise da arborização de vias públicas de Maringá-PR. Revista SBAU, Piracicaba, v. 3, n. 1, p. 37-57, 2008.

SILVA, A. G.; PAIVA, H. N. de.; GONÇALVES, W. Avaliando a Arborização Urbana. Viçosa:
Aprenda Fácil, 2007. 346 p. (Coleção Jardinagem e Paisagismo, Série Arborização Urbana, v. 5).

SILVA FILHO, D. F. et al. Banco Relacional para Cadastro, Avaliação e Manejo da Arborização em Vias Públicas. Revista Árvore, Viçosa, v. 26, n. 5, p. 629-612, 2002.

SILVA, L. B. et al. Monitoramento da Qualidade do Ar Através de Bioindicadores. In: SEMINÁRIO NACIONAL DE PRODUÇÃO E TRANSMISSÃO DE ENÉRGIA ELÉTRICA, 15. 1999. Foz do Iguaçu. Anais... Foz do Iguaçu, 1999.

SILVA, M. D. M.; SILVEIRA, R. P.; TEIXEIRA, M. I. J. G. Avaliação da arborização de vias públicas de uma área da região oeste da cidade de Franca/ SP. Revista SBAU, Piracicaba, v. 3, n. 1, p. 19-35, mar. 2008.

TEIXEIRA, I. F. Análise qualitativa da arborização de ruas do conjunto habitacional Tancredo Neves, Santa Maria - RS. Ciência Florestal, Santa Maria, v. 9, n. 2, p. 9-21. 1999.

VITÓRIA. Prefeitura Municipal de Vitória. Plano Diretor de Arborização e Áreas Verdes. Vitória, 1992. $97 \mathrm{p}$. 